\title{
Cost-effectiveness analysis of newborn pulse oximetry screening to detect critical congenital heart disease in Colombia
}

\author{
Dario Londoño Trujillo ${ }^{1 *}$, Nestor Fernando Sandoval Reyes ${ }^{2}$, Alejandra Taborda Restrepo ${ }^{1}$, \\ Cindy Lorena Chamorro Velasquez ${ }^{1}$, Maria Teresa Dominguez Torres ${ }^{3}$, Sandra Vanessa Romero Ducuara², \\ Gloria Amparo Troncoso Moreno ${ }^{4}$, Hernan Camilo Aranguren Bello ${ }^{3}$, Alejandra Fonseca Cuevas ${ }^{3}$, \\ Pablo Andres Bermudez Hernandez $z^{3}$, Pablo Sandoval Trujillo ${ }^{5}$ and Rodolfo Jose Dennis ${ }^{3}$
}

\begin{abstract}
Background: In many countries, economic assessments of the routine use of pulse oximetry in the detection of Critical Congenital Heart Disease (CCHD) at birth has not yet been carried out. CCHDs necessarily require medical intervention within the first months of life. This assessment is a priority in low and medium resource countries. The purpose of this study was to assess the cost-effectiveness (CE) relation of pulse oximetry in the detection of cases of CCHD in Colombia.
\end{abstract}

Methods: A full economic assessment of the cost-effectiveness type was conducted from the perspective of society. A decision tree was constructed to establish a comparison between newborn physical examination plus pulse oximetry, versus physical examination alone, in the diagnosis of CCHDs. The sensitivity and specificity of pulse oximetry were estimated from a systematic review of the literature; to assess resource use, micro-costing analyses and surveys were conducted. The time horizon of the economic evaluation was the first week after birth and until the first year of life. The incremental cost-effectiveness ratio (ICER) was determined and, to control for uncertainty, deterministic and probabilistic sensitivity analysis were made, including the adoption of different scenarios of budgetary impact. All costs are expressed in US dollars from 2017, using the average exchange rate for 2017 [\$2,951.15 COP for 1 dollar].

Results: The costs of pulse oximetry screening plus physical examination were $\$ 102 ;$; higher than physical examination alone. The effectiveness of pulse oximetry plus the physical examination was 0.93 ; that is, 0.07 more than the physical examination on its own. The ICER was $\$ 100$ for pulse oximetry screening; that is, if one wishes to increase $1 \%$ the probability of a correct CCHD diagnosis, this amount would have to be invested. A willingness to pay of $\$ 26.292$ USD (direct medical cost) per probability of a correct CCHD diagnosis was assumed.

Conclusions: At current rates and from the perspective of society, newborn pulse oximetry screening at $24 \mathrm{~h}$ in addition to physical examination, and considering a time horizon of 1 week, is a cost-effective strategy in the early diagnosis of CCHDs in Colombia.

Trial registration "retrospectively registered".

Keywords: Cost-effectiveness analysis, Congenital heart defects, Diagnosis, Pulse oximetry, Indirect expenditures

\footnotetext{
*Correspondence: dario.londono@fsfb.org.co

1 Public Health Division, Fundacion Santa Fe de Bogota, Carrera 7 B \#

123-90, 5 Piso, Bogotá, Colombia

Full list of author information is available at the end of the article
} 


\section{Background}

Critical congenital heart diseases (CCHD) make up a group of structural defects of the heart that are present from the prenatal period and represent more than a third of all congenital heart cardiopathies [1, 2]; at world level, their incidence ranges from 1 in 15,000 to 1 in 26,000 live births and their prevalence is 147.4 per 100,000 live births [3]. Amongst the main CCHDs we find Pulmonary Atresia, Tetralogy of Fallot, Tricuspid Atresia, Truncus Arteriosus, Hypoplastic Left Heart Syndrome, Total Anomalus Pulmonary Venous Return and the Transposition of Great Vessels. These diseases generate an important morbidity and mortality burden from the first month of the infant's life, and hence it is necessary to perform surgical and/or early interventional treatment $[2,4]$.

The early detection of these cardiopathies can help to significantly modify the clinical course of patients with CCHD. This detection may take place in different ways before birth, as in the case of prenatal ultrasound and anatomic ultrasound testing. However, prenatal detection of these cases is still underused in many countries. Almost 30\% of newborns affected are diagnosed late [5], which means an untimely medical-surgical intervention, with a high morbidity and mortality rate [6].

After birth, CCHDs may be identified by physical examination within the first $24 \mathrm{~h}$ and through other diagnostic tests like EKG or chest X-ray; however, these tests lack the necessary sensitivity to detect most cases [6]. For this reason, it is necessary to consider other early detection techniques such as pulse oximetry, which is a highly sensitive, well-established, non-invasive test for the objective quantification of hypoxemia, which may be suitable for the routine screening of CCHD $[7,8]$. Use of this screening method for early detection of congenital heart defects is based on the rationale that clinically undetectable hypoxemia is present, to some degree, in most potentially life-threatening cases. Pulse oximetry has been previously assessed as a screening method for congenital heart defects in newborns [8]. The primary benefit of newborn screening for CCHD with pulse oximetry is timely identification before hospital discharge, thereby minimizing the morbidity and mortality associated with delayed diagnosis [9-11].

From the standpoint of technology assessment, pulse oximetry has shown to be cost-effective in countries like the United States, the United Kingdom and China [12]. In studies published conducted in these countries, mainly from the perspective of the health system and with a time horizon of less than a year, comparing pulse oximetry with the clinical general examination ended with the correct diagnosis of $\mathrm{CCHD}$ or the number of deaths avoided [13-15].
In countries like Colombia, the universal use of pulse oximetry $24 \mathrm{~h}$ after birth, in addition to standardized physical examination of the newborn as a strategy for screening congenital heart disease is recommended $[16,17]$. However, in spite of the recommendations and availability of the technology, clinical experts on the subject state that this clinical practice has not been widely accepted on a regular basis in Colombia: a local study on the subject showed that only $25 \%$ of the physicians in the survey know and apply neonatal screening in a correct way [18].

The purpose of this study was to assess the cost-effectiveness of pulse oximetry plus physical examination in the correct and timely detection of CCHDs, when compared with physical examination alone, and to estimate the likely budget impact of its gradual implementation in clinical practice, as a new national policy.

\section{Methods}

\section{Economic assessment}

A cost-effectiveness study from the societal perspective was proposed. This study included direct and indirect costs associated with the outcomes, which are covered by the general social security system (SGSSS) and families, and compared the use of pulse oximetry screening in addition to general physical examination with the general physical examination alone. Health outcomes were measured as correct diagnosis and survival. The target population of the study was a hypothetical cohort of nonpremature newborns, up to the first $24 \mathrm{~h}$ after birth.

Prognosis in CCHD is directly dependent on a timely diagnosis; therefore, the time horizon for the economic evaluation was defined according to two related outcomes: firstly, (a) the probability of a correctly diagnosed CCHD at 1 week of age; and secondly, (b) survival at 12 months. Both assumptions were considered based on the natural history of the disease (according to the literature and the consensus of clinical experts in the management of CCHD). In view of the time horizon of less than a year, it was not necessary to apply discount rates.

With the purpose of estimating costs and the potential benefits, a decision tree was proposed which reflects the possible outcomes for the term newborn diagnosed by alternatives compared within the time horizon defined: (a) after one week (cases correctly diagnosed) and (b) the first year of life (overlife) (Fig. 1).

In this model it was assumed that the general examination corresponds to the examination conducted by the general, not specialized physician. In the case of a positive diagnosis for CCHD (with any alternative), confirmation tests were included according to the assistance algorithm depending on the altitude above sea level. The altitude above sea level at which oximetry 


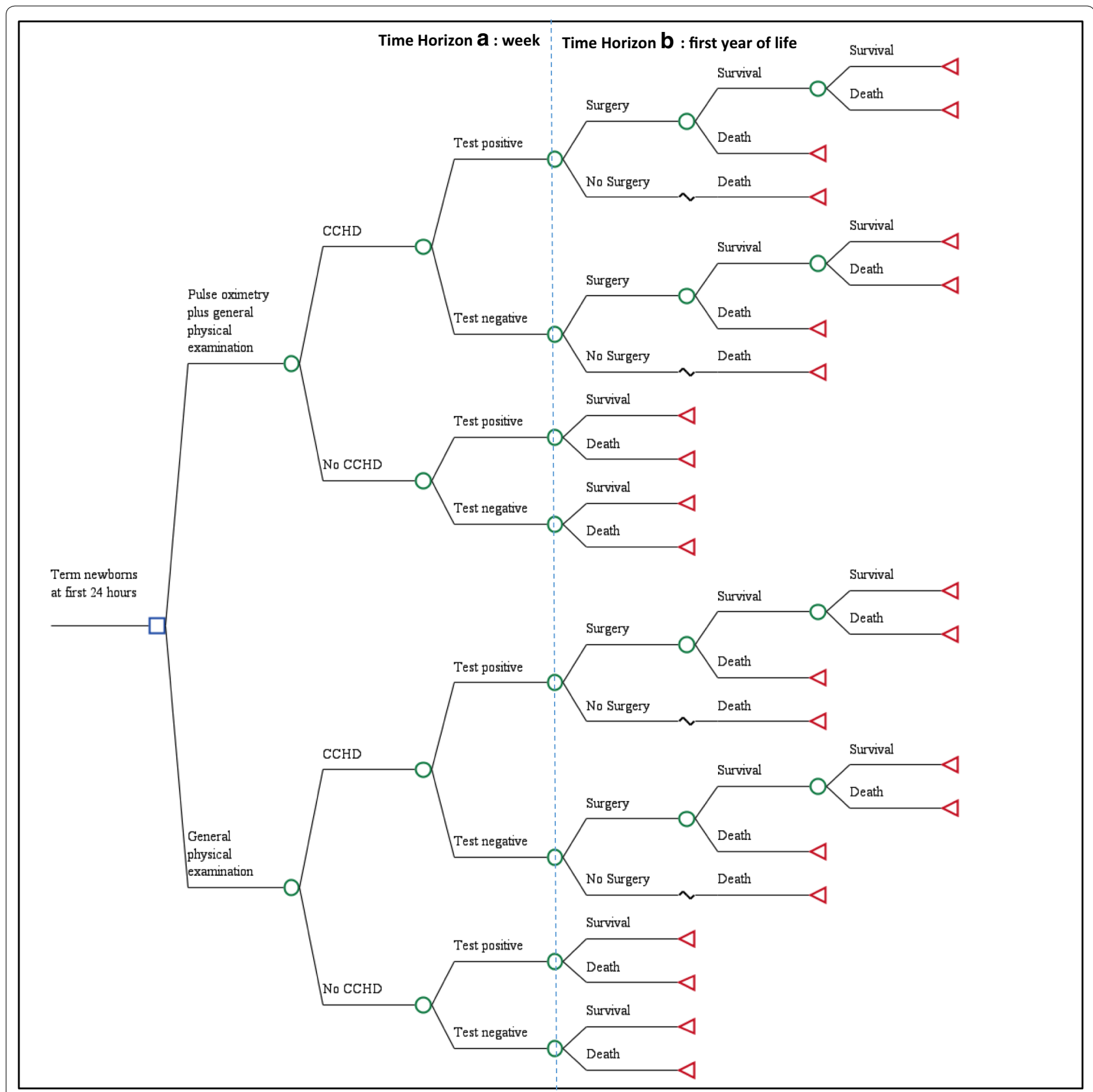

Fig. 1 Decision tree

(SatO2) is measured influences the SatO2 cut-off point chosen to rule-out disease (as altitude increases, atmospheric pressure and SatO2 decrease in normal subjects as well) [19]. Colombia has an altitude range varying from zero to $6000 \mathrm{~m}$ above sea level (MASL), and its more densely populated geographical areas are located between 1000 and 2700 MASL. Thus, the design of a screening algorithm with different SatO2 cutoff points (allowing for different MASL) was necessary. During the first week, indirect costs relevant to the families are not included. Lastly, it was considered that if newborns had a CCHD diagnosis and were not medically intervened within the first year, mortality rates would reach $100 \%$.

Expected costs and outcomes of each strategy were estimated in TreeAge Pro ${ }^{\circledR} 2017$. 


\section{Effectiveness}

The choice of health outcomes (correct diagnosis and survival) were validated with experts in the diagnosis and treatment of CCHDs. In order to estimate event probabilities in the model, four systematic literature reviews (SLR) were conducted: sensitivity and specificity of both tests: pulse oximetry associated with general physical examination, and general physical examination alone [20]; the likely prevalence of CCHD; and CCHD mortality estimates with and without-delayed surgical treatment. The search for SLRs on the prevalence of CCHDs was performed in Pubmed, Embase, Ovid, Scopus, LILACS and TRIPDatabase. We included longitudinal, prospective, retrospective, cross-sectional, cohort, and case studies published between 2011 and 2016, published in English, Spanish or French. The SLR on the sensitivity and specificity of both tests (pulse oximetry associated with the general physical examination and the general physical examination alone) was conducted in Pubmed, Science Direct, Ovid and EBSCO; in this review we included systematic reviews, meta-analysis, case and control studies and cohort studies published between 2002 and 2016, regardless of the language. For the SLR on CCHDs mortality, a search was made in Scopus and Pubmed including retrospective studies in English, French and Spanish from 2011 to 2017, and for the SLR on mortality post-surgical intervention, the search was made in Pubmed, Sciencedirect, LILACS, Ebsco- Host, Cochrane, Scopus, including cohort and case and control studies in English and Spanish, between 2012 and 2017 (Table 1).
Given that the probability of death as a result of late diagnosis was not found in the literature, it was estimated following the methodology suggested by Grigore et al. $[22,23]$ to obtain event probabilities from clinical experts. For this, clinical experts (15 pediatric cardiologists) were given two scenarios and asked to give their estimate on the proportion of patients who would die in each one of them: (A) the patient has a CCHD, diagnosis is confirmed, but for some reason $\mathrm{s} /$ he does not undergo surgery; and (B) the patient has a CCHD, the diagnosis is not considered and $\mathrm{s} /$ he does not undergo surgery (Table 2).

\section{Costs}

To estimate direct costs, a micro-costing analysis was made by reviewing the clinical records of $73 \mathrm{CCHD}$ patients from the databasaes of a hospital specialized in the management of CCHDs in the city of Bogota. To estimate indirect costs, a survey was applied to 20 caregivers of patients with CCHDs. This survey asked caregivers about the out-of-pocket expenses incurred by family and any days of leave from work related with patient care. Indirect costs were established by means of the human capital approach, with average daily income calculated based on the distribution of reported income by all caregivers surveyed. Medical direct costs were valued at market prices, using as reference standard fees from Colombia's Social Security manual. Generally, contracts between insurers and providers of health services is based on this national tariff manual (called ISS 2001); prices in this manual are adjusted in the negotiation, and

Table 1 Effectiveness parameters used in the model

\begin{tabular}{lllll}
\hline Effectiveness & Base (average) & Minimum & Maximum & Source \\
\hline Prevalence of CCHD & 0.014 & 0.006 & 0.032 & SRL \\
Sensitivity of general examination & 0.5878 & 0.115 & 0.892 & SRL \\
Specificity of general examination & 0.8631 & 0.4 & 0.99 & $\mathrm{SRL}$ \\
Sensitivity of pulse oximetry & 0.8869 & 0.8276 & 0.955 & $\mathrm{~S}$ \\
Specificity of pulse oximetry & 0.9325 & 0.665 & 0.998 & $\mathrm{~S}$ \\
CCHD mortality & 0.143 & 0.026 & 0.795 & $\mathrm{SRL}$ \\
Mortality post-intervention & 0.0917 & 0.018 & 0.1702 & $\mathrm{SRL}$ \\
General mortality under 1 year in Colombia & 0.017 & 0.01 & 0.02 & DANE [21]
\end{tabular}

CCHD critical congenital heart disease, DANE administrative department of national statistics

Table 2 Effectiveness parameters not available in the literature

\begin{tabular}{lll}
\hline Effectiveness parameters & Base (average) & Maximum \\
\hline $\begin{array}{l}\text { Probability of death with no surgery but diagnosis was confirmed } \\
\text { Probability of death with no surgery and diagnosis not considered (false nega- }\end{array}$ & 0.69 & 0.08 \\
tive) & & 0.94 \\
\hline
\end{tabular}


$35 \%$ represents the most common current mark-up used for most economic evaluations in Colombia. All costs are given in USD, using the average exchange rate for 2017 [\$2,951.15 pesos for 1 dollar] [24] (Table 3).

\section{Cost-effectiveness criteria}

In order to establish whether an intervention is costeffective, the cost-effectiveness ratio observed must be compared with a cost-effectiveness threshold. Given that the economic evaluation considered two scenarios with different times and outcomes, two different thresholds were considered as well: (1) for a correctly diagnosed CCHD case (1 week of life), a threshold of USD 26.292 was selected (which corresponds to the average direct medical costs of a patient with CCHD); and (2) for probability of survival (at 1 year), a threshold of USD 6.408, the gross domestic product (GDP) per capita in Colombia according to the World Bank [26].

\section{Sensitivity analysis to assess the role of uncertainty}

Two types of analysis were conducted: (a) a deterministic analysis, which considers point estimates and confidence intervals of each parameter and is presented through a tornado diagram; and (b) probabilistic sensitivity analysis (PSA). In PSA, uncertainty was assessed through Montecarlo simulation and a hypothetical cohort of patients (1000 iterations). A triangular distribution was assigned to costs, and a beta distribution to probabilities and utilities. Results of PSA were illustrated as cost-effectiveness acceptability curves, which show the probability that an alternative is cost-effective for different willingness-topay thresholds.

\section{Budget impact analysis (BIA)}

The BIA makes it possible to estimate how much a health system must invest or how much is saved due to the routine use of some technology. The calculation is based on the consideration of two scenarios: a current one, which refers to the treatment indicated for the health condition, with the technologies available within the coverage of the benefits plan for the social security system (SGSSS) or which are being financed with public resources; and a second scenario, called the new one, which describes the treatment that incorporates the new technology or technologies subjected to assessment. The budget impact analysis followed recommendations of the International Society for Pharmacoeconomics and Outcomes Research (ISPOR) [27] and the Colombian Agency of Health Technology Assessment (IETS from its Spanish initials) [28]. Table 4 shows the sources of information used in the calculation of budget impact of a gradual increase in the detection of CCHDs by means of pulse oximetry in the clinical practice in Colombia (Table 4).

Through this analysis, if the result is positive, it is interpreted as the financial effort the country should make to finance this technology. Conversely, if the impact is negative, it means that the country would be saving this cost by using the technology.

\section{Results}

\section{Economic assessment}

For the time horizon of 1 week (outcome of correctly detected cases), the cost of pulse oximetry screening plus the general examination, versus the general examination alone was $\$ 102$ and $\$ 95$ respectively. The effectiveness of pulse oximetry plus the general examination, versus the general examination alone was 0.93 and 0.86 respectively. The incremental cost-effectiveness ratio (ICER) was $\$ 100$ for pulse oximetry screening; that is, if one wishes to increase in $1 \%$ the probability of a correct CCHD diagnosis, this amount would have to be invested (Table 5). Under the agreed willingness to pay, pulse oximetry would be cost-effective.

Table 3 Cost parameters used in the model

\begin{tabular}{lcccl}
\hline Costs & Base (average) & Minimum & Maximum & Source \\
\hline Pulse oximetry + general examination & $\$ 60$ & $\$ 25$ & $\$ 117$ & Own calculations \\
& & & ISS 2001 \\
General examination & $\$ 19$ & $\$ 9$ & $\$ 35$ & ISS 2001 \\
Confirmatory tests & $\$ 530$ & $\$ 425$ & $\$ 1055$ & ISS 2001 \\
Average cost hospital events for CCHD & $\$ 25,835$ & $\$ 16,904$ & $\$ 42,419$ & Cost estimation through clinical records, ISS 2001 valuation \\
Ambulatory cost of CCHD & $\$ 457$ & $\$ 449$ & $\$ 533$ & Construction with experts, ISS 2001 valuation \\
Indirect costs of CCHD with no surgery & $\$ 775$ & $\$ 42$ & $\$ 1000$ & Construction by authors through surveys of caregivers \\
Indirect costs of CCHD with surgery & $\$ 1466$ & $\$ 333$ & $\$ 3802$ & \\
Out-of-pocket expenses with no surgery & $\$ 1083$ & $\$ 28$ & $\$ 3106$ & \\
Out-of-pocket expenses with surgery & $\$ 2383$ & $\$ 204$ & $\$ 5732$ & \\
Indirect costs of death & $\$ 678$ & $\$ 237$ & $\$ 3389$ & Funerary expenses in Colombia, Protection Businees Group [25] \\
\hline
\end{tabular}


Table 4 Methodological case of the budget impact analysis

\begin{tabular}{ll}
\hline Technologies assessed & (a) General examination with pulse oximetry \\
& (b) General examination \\
Population & Term newborns in Colombia \\
& Demographical growth as from DANE projections \\
& Epidemiological information (prevalence of CCHDs) taken from SLR \\
Perspective & Health system - third payer \\
Time horizon & Every scenario: 1 year \\
& Three scenarios are compared \\
Costs included & See Table 3 (costs associated to the detection of CCHD) \\
& The base case corresponds to the current scenario, without the use of pulse oximetry \\
Sources of information & Costs deriving from the economic assessment \\
& Prevalence derived from SLR \\
Scenarios & Current scenario: pulse oximetry: $0 \%$ \\
& New scenario a: pulse oximetry $10 \%$ \\
Results & New scenario b: pulse oximetry $20 \%$ \\
& The difference among estimated scenarios (current and new), expressed as follows: \\
& Budget impact = New scenario-current scenario
\end{tabular}

DANE the national administrative department of statistics, SLR systematic literature review

Table 5 Cost-effectiveness results baseline case as per outcome

\begin{tabular}{|c|c|c|c|c|c|c|}
\hline Alternative & & Cost & $\begin{array}{l}\text { incremental } \\
\text { cost }\end{array}$ & $\begin{array}{l}\text { Effectiveness } \\
\text { correctly detected } \\
\text { case }\end{array}$ & $\begin{array}{l}\text { Incremental } \\
\text { effectiveness }\end{array}$ & $\begin{array}{l}\text { ICER correctly } \\
\text { detected case }\end{array}$ \\
\hline \multirow[t]{2}{*}{ One week } & General examination & $\$ 95$ & & 0.86 & & \\
\hline & Pulse oximetry plus general examination & $\$ 102$ & $\$ 7$ & 0.93 & 0.07 & $\$ 100$ \\
\hline Alternative & & Cost & $\begin{array}{l}\text { Incremental } \\
\text { cost }\end{array}$ & $\begin{array}{l}\text { Over life } \\
\text { effectiveness }\end{array}$ & $\begin{array}{l}\text { Incremental } \\
\text { effectiveness }\end{array}$ & Survival ICER \\
\hline \multirow[t]{2}{*}{ First year of life } & General examination & $\$ 326$ & & 0.9745 & & \\
\hline & Pulse oximetry plus general examination & $\$ 365$ & $\$ 39$ & 0.9755 & 0.001 & $\$ 39,050$ \\
\hline
\end{tabular}

ICER incremental cost-effectiveness ratio

For the results at 1 year of life, considering the mortality associated with CCHD and with medical intervention, the oximetry strategy plus general examination is more effective but more expensive: it would be necessary to invest a large amount of money $(\$ 39,050)$ to obtain a $1 \%$ increase in survival, when compared with only general physical examination (Table 5).

\section{Deterministic sensitivity analysis}

Correctly detected cases: The tornado diagram is shown, and in descending order the variables having most influence on the incremental results (Fig. 2). The most sensitive variables are the specificity of pulse oximetry, followed by costs.

The cost of doing pulse oximetry may be subject to controversy; that is why a one-way sensitivity analysis was performed for this variable. It was found that even with the highest cost of the alternative assessed $(\$ 81)$ the result continues to be cost-effective (Table 6).
The tornado analysis of the model up to the first year of life (Fig. 3), the prevalence of CCHD, the probability of surgery among the correctly diagnosed cases, the hospital costs and the specificity of the general physical examination are the variables most influencing the results.

As the prevalence of CCHDs is an element of high impact for the analysis, it was made by taking into account all the possible ranges, whereby for all cases it is necessary to make a high investment $(\$ 37,494$ to $\$ 44,273)$ to improve effectiveness by $1 \%$ as compared with the general examination only (Table 7).

\section{Probabilistic sensitivity analysis}

Pulse-oximetry was found to have a larger probability to be cost-effective as the availability to pay increases (Fig. 4).

\section{Results of budget impact}

In the current scenario, a $0 \%$ use of pulse oximetry was assumed; thus, the number of cases of CCHD detected 


\section{Tornado Analysis (Net Benefits)}

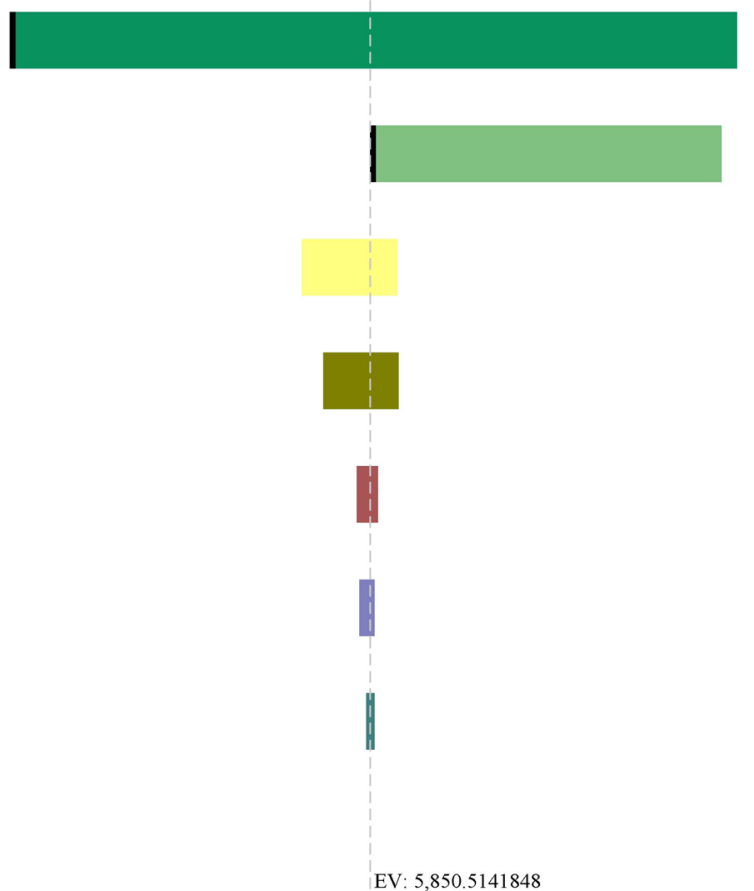

Specificity_pulseoximetry ( 0.665 to 0.998 )

Specificity_general (0.4 to 0.99)

Cost_confirmatory_tests (105.0 to 1,585.0)

Cost_pulseoximetry (25.0 to 117.0)

Cost_general (9.0 to 35.0)

Prevalence_CCHD (0.006 to 0.032)

Sensitivity pulseoximetry ( 0.8276 to 0.955$)$

Sensitivity_general (0.115 to 0.892$)$

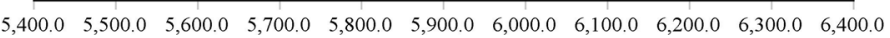

Fig. 2 Tornado analysis of results — first week of life

Table 6 One-way sensitivity analysis: the cost of pulse oximetry

\begin{tabular}{|c|c|c|c|c|c|c|}
\hline $\begin{array}{l}\text { Cost of pulse } \\
\text { oximetry }\end{array}$ & Alternative & Cost & Effectiveness & Incremental cost & $\begin{array}{l}\text { Incremental } \\
\text { effectiveness }\end{array}$ & ICER \\
\hline \multirow[t]{2}{*}{$\$ 16$} & Pulse oximetry plus general examination & $\$ 77$ & 0.931862 & $\$-$ & 0 & $\$-$ \\
\hline & General examination & $\$ 95$ & 0.859246 & $\$ 18$ & -0.07262 & $(\$ 244)$ \\
\hline \multirow[t]{2}{*}{$\$ 81$} & General examination & $\$ 95$ & 0.859246 & $\$-$ & 0 & $\$ 0$ \\
\hline & Pulse oximetry plus general examination & $\$ 142$ & 0.931862 & $\$ 47$ & 0.072616 & $\$ 653$ \\
\hline
\end{tabular}

ICER incremental cost-effectiveness ratio

are the result of the general physical exam only (2790 cases). For the second year, with the implementation of pulse oximetry in $10 \%$ of the newborns, the number of cases detected would be 3241; 425 more cases than in the scenario with screening by the general physical examination only. In the third year, with the implementation for $20 \%$ of the cases, 858 cases more would be detected. Table 8 shows the results of the budget impact analysis of the diagnosis and treatment of diagnosed cases. With the scenario of a $10 \%$ use of pulse oximetry, the budget impact for the SGSSS is $\$ 2,512,359$ in the diagnostic phase, and in the assistance of new cases detected, there is an increase of $\$ 7,410,700$ in costs. These values consider direct medical costs only.

\section{Discussion}

This economic assessment shows that the addition of pulse oximetry to the general physical examination of the newborn, is a cost-effective alternative to correctly detect CCHD cases at birth, with a time horizon of 1 week.. However, using a wider time horizon and considering survival, the strategy would not be cost-effective in Colombia, as it would exceed the cost-effectiveness threshold.

This is the first full economic assessment published on the subject in Latin America, considering the perspective of society and measuring the budget impact for the SGSSS. The results of this study may be compared with other economic assessments around the 


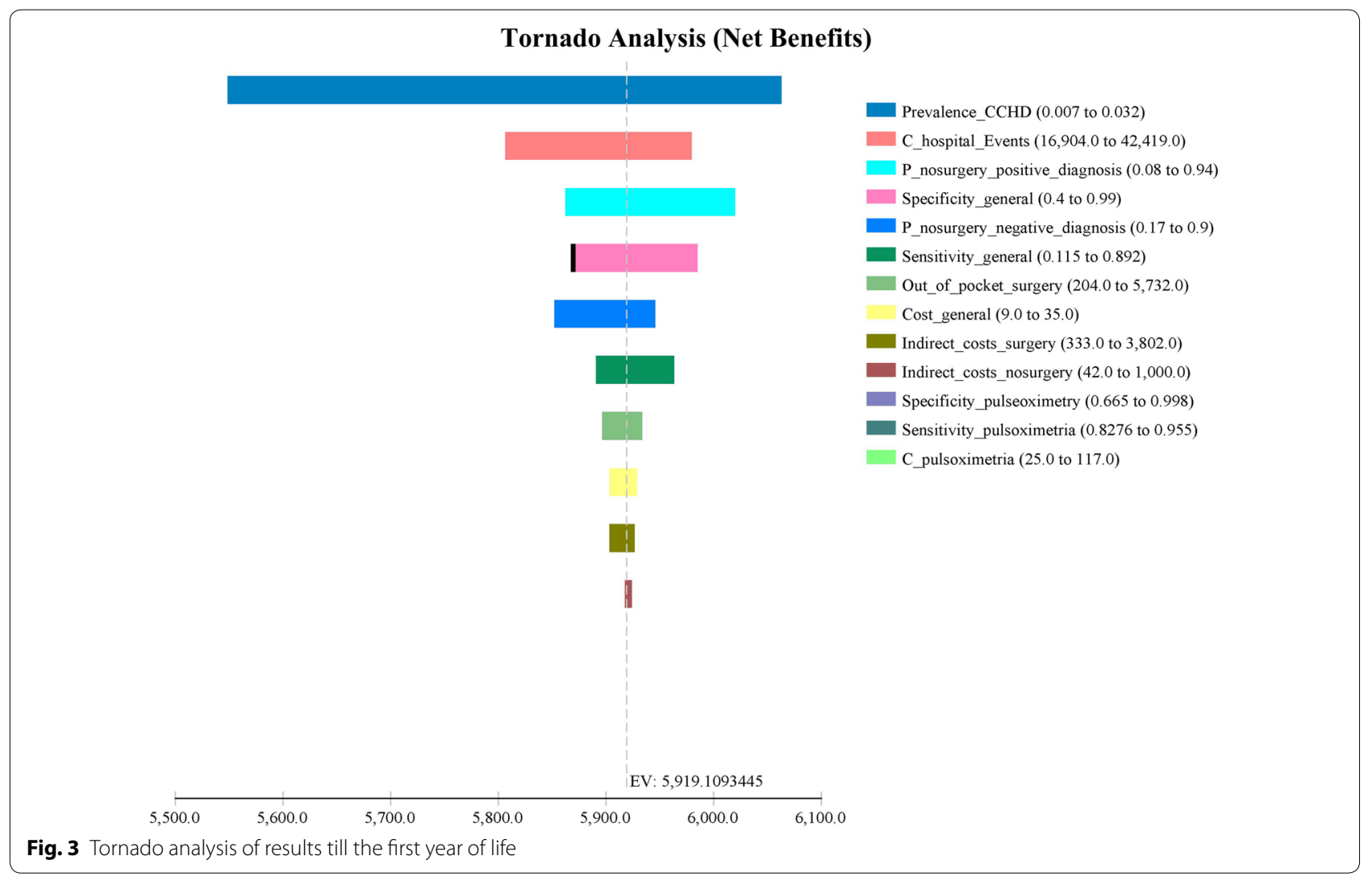

Table 7 Sensitivity analysis of one parameter: prevalence

\begin{tabular}{|c|c|c|c|c|c|c|c|}
\hline Estimates & Name of the variable & Strategies & Costs & Effectiveness & $\begin{array}{l}\text { Incremental } \\
\text { cost }\end{array}$ & $\begin{array}{l}\text { Incremental } \\
\text { effectiveness }\end{array}$ & ICER \\
\hline \multirow[t]{2}{*}{0.007} & Prevalence of CCHD & General physical examination & $\$ 209$ & 0.978769 & $\$-$ & 0 & $\$-$ \\
\hline & Prevalence of CCHD & Pulse oximetry + general physical examination & $\$ 230$ & 0.979258 & $\$ 22$ & 0.000489 & $\$ 44,273$ \\
\hline \multirow[t]{2}{*}{0.032} & Prevalence of CCHD & General physical examination & $\$ 627$ & 0.963658 & $\$-$ & 0 & $\$-$ \\
\hline & Prevalence of CCHD & Pulse oximetry + general physical examination & $\$ 711$ & 0.965893 & $\$ 84$ & 0.002235 & $\$ 37,494$ \\
\hline
\end{tabular}

ICER incremental cost-effectiveness ratio

world. Studies like the one conducted by Peterson et al. in the United States [13] found a cost-effectiveness ratio of USD 40,385 (prices for 2011) per year of life earned, when identifying 1189 additional newborns with CCHD in the hospitals where they were born through pulse oximetry, and preventing 20 additional infant deaths per year. In the United Kingdom, Roberts et al. [14] performed a cost-effectiveness analysis with the same purpose, comparing pulse oximetry as a complement for the clinical examination versus the clinical examination on its own to detect congenital heart disease in newborns. The ICER was $£ 24,000$ per case diagnosed in time; they concluded that pulse oximetry is a cost-effective strategy in the light of the threshold defined by the United Kingdom. In China, this strategy was also assessed in the detection of CCHD; the study shows how pulse oximetry reduces the burden of the disease in terms of years of life lost by premature death [15].

The results of the costs estimates showed a high economic impact of CCHD on the Colombian health system and on families. Regarding indirect costs, no studies were found tackling this topic in CCHDs; however, an approximation was made by Raj et al. [29] in a study on patients with congenital heart disease, in which they found that the mean loss of days by parents was 35 and the loss of working days was 15 days on average. Mughal et al. [30.] identified that $12.3 \%$ of families contributed totally to the 


\section{CE Acceptability Curve}

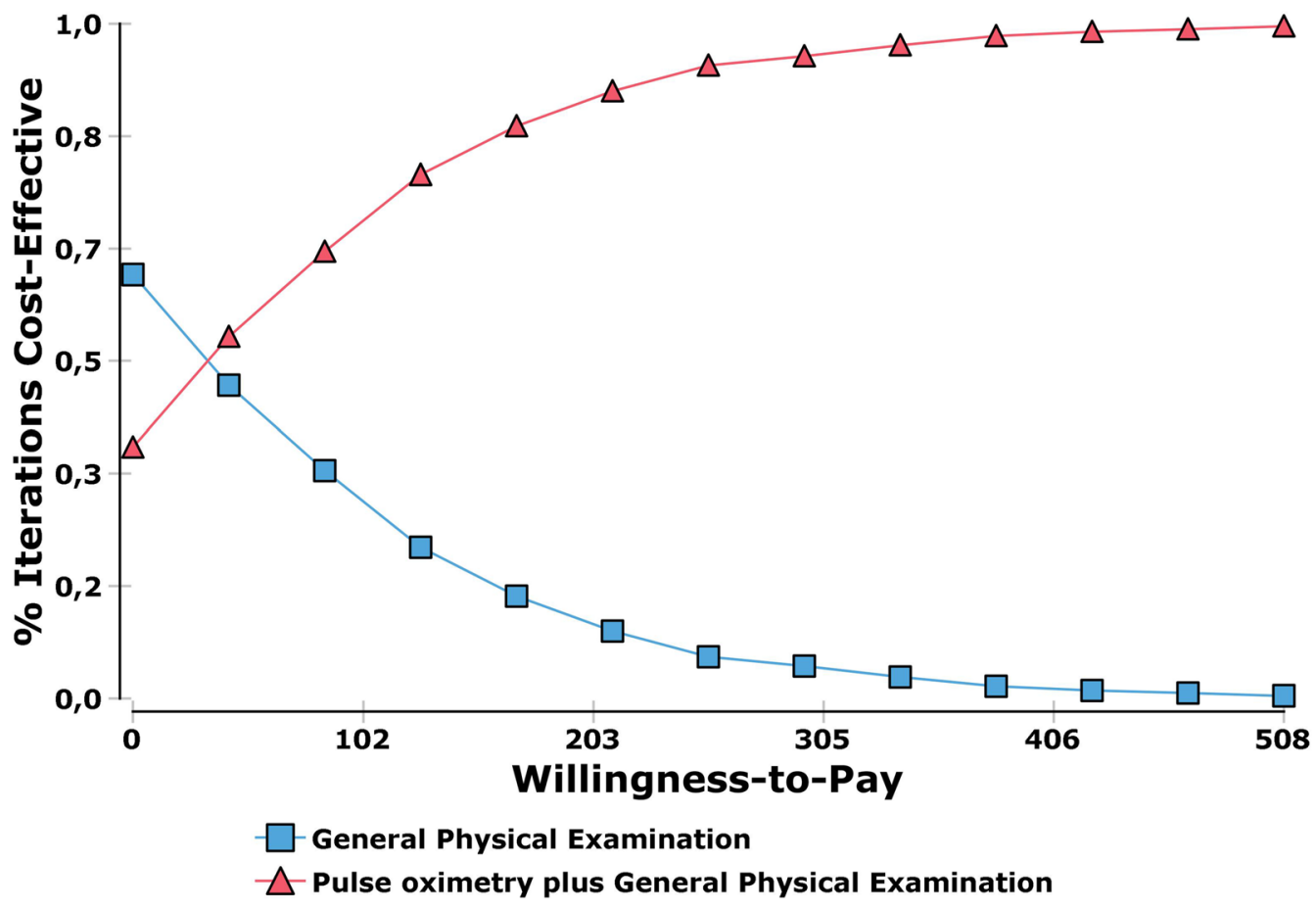

Fig. 4 Probabilistic sensitivity analysis: cost-effectiveness acceptability curve

Table 8 Budget impact of diagnosis and treatment

Current scenario

$\$-$

Cost of pulse oximetry

Cost of general physical examination

Total cost of CCHD detection

Budget impact of diagnosis

Costs incurred by detection

Medical indirect costs

Budget impact of treatment

Second year new scenario (10\%)

Third year new

Scenario (20\%)

$C C H D$ critical congenital heart disease

cost associated with the treatment of patients, and $63.1 \%$ of families partly contributed to the total cost.

The budget impact with a scenario of $10 \%$ was $\$ 2,512,359$ and for a $20 \%$ scenario it corresponds to $\$ 5,069,018$. Although pulse oximetry is included in the compulsory health plan (POS from its Spanish initials) of the SGSSS, namely the aspects or activities covered by the health system and paid by insurance companies, which are recommended in favor of the correct and timely detection of congenital anomalies, we define this level of percentage implementation because there are still many challenges to overcome before pulse oximetry is taken to clinical practice; among these challenges we find the training of health professionals, the codification of health plans, the forms of contracting with hospitals and the availability of technology in the country, considering that the majority of the population are located in rural areas and rural disperse areas, whereas qualified assistance centers are located in the main cities of the country. 
As strengths for this study, none of the studies published in other countries considers a perspective of society nor the budget impact on the country derived from the implementation of the technology assessed. To include the social perspective in the assessment, it was necessary to perform a costs estimate by means of an extensive process which included different sources of information to perform cost estimates considering the costs incurred by the health system and the families. This aspect of the out-of-pocket expenses by the families required an additional effort in order to collect information from primary sources through surveys, considering as well the low prevalence of CCHDs. In addition to this, this study developed a rigorous, reproducible methodology to establish or document probabilities from the opinion of clinical experts.

\section{Conclusions}

From the perspective of the Colombian society and considering a time horizon of 1 week, this economic evaluation shows that a screening strategy of pulse oximetry plus general physical examination is cost-effective in the detection of CCHD in term newborns, when compared with general physical examination alone, This study also provides the necessary information to consider its national implementation for routine use in clinical practice.

\section{Abbreviations \\ CCHD: critical congenital heart disease; SGSSS: Colombian General System of Health Social Security; SLR: systematic literature review; WTP: willingness to pay.

\begin{abstract}
Acknowledgements
We wish to thank the supporting staff for the Program for Innovation in Infrequent Congenital Human Cardiopathies (PINOCCHIO from its Spanish acronym); the Help Desk at $\mathrm{FCl}-\mathrm{IC}$ on their willingness and support to get the databases according to the specific needs of the project, especially Engineer Maricela Atara Martínez, on her permanent collaboration, Jonathan Campos and Oscar Rodríguez, former research assistants for the project, during the resources in clinical records, Dayan Roa for her help in the search for care providers to take the survey on indirect costs; Aurelio Mejía for doing the methodological assessment of the cost-effectiveness analysis.
\end{abstract} initial information collection stage; Juan Novoa on his cooperation to validate}

\section{Authors' contributions}

$\mathrm{RD}$ and $\mathrm{DL}$ designed the study protocol. AT, DL worked on the design; VR conducted the search for the 73 patients with CCHD for the database for the estimation of direct medical costs. MD supported the process of requesting and delivering the database. CC organized the information and conducted the descriptive analysis of the information on costs. AF, CA, PB, PS did the SLR for effectiveness parameters; NS, GT, MD, RD validated the information on the natural history of the disease in order to propose the model. AT, CC ran the model in TreeAge. AT, CC, GT, CA, AF, PB, PS, RD, MD, DL validated the economic assessment process. All authors read and approved the final manuscript.

\section{Funding}

This study is financed by the Colombian Fund for the Financing of Science, Techology and Innovation, Francisco José de Caldas-COLCIENCIAS, Program for Innovation in Infrequent Congenital Human Cardiopathies (PINOCCHIO from its Spanish acronym) — Contract 662-2015.

\section{Ethical approval and consent to participate}

The ethical approval for the project was awarded by the Clinical Research Ethics Committee at FCl-IC (CEIC) for the supply and access to the database of patients with CCHD and for the collection of information on care providers. The informed consent was provided to be filled in by the case report form (CRF) of patients from the PINOCCHIO Program Cohort, whereby information on out-of-pocket expenses and indirect costs of every care provided was obtained from those answering the survey.

\section{Consent for publication \\ Not applicable}

\section{Availability of data and materials}

The datasets generated and/or analysed during the current study are available in the following link https://www.dropbox.com/sh/lk7mxop3px9zgiy/AABAv bBIHvHY9C2eLOOafmXwa?dl=0

\section{Competing interests}

The authors declare that they have no competing interests

\section{Author details}

1 Public Health Division, Fundacion Santa Fe de Bogota, Carrera 7 B \# 123-90, 5 Piso, Bogotá, Colombia. ${ }^{2}$ Institute of Congenital Heart Disease, Fundacion Cardioinfantil-Institute of Cardiology, Bogotá, Colombia. ${ }^{3}$ Research Department, Fundacion Cardioinfantil-Institute of Cardiology, Bogotá, Colombia.

${ }^{4}$ Neonatal Unit, Pediatrics Department, Fundacion Cardioinfantil-Institute of Cardiology, Bogotá, Colombia. ${ }^{5}$ School of Medicine, Universidad de los Andes, Bogotá, Colombia.

Received: 11 October 2018 Accepted: 10 June 2019

Published online: 24 June 2019

References

1. Olney RS, Ailes EC, Sontag MK. Detection of critical congenital heart defects: review of contributions from prenatal and newborn screening. Semin Perinatol. 2015;39(3):230-7.

2. Harold JG. Screening for critical congenital heart disease in newborns. Circulation. 2014;130(9):e79-81.

3. Schultz AH, Localio AR, Clark BJ, Ravishankar C, Videon N, Kimmel SE. Epidemiologic features of the presentation of critical congenital heart disease: implications for screening. Pediatrics. 2008;121(4):751-7.

4. Bruno $C J$, Havranek T. Screening for critical congenital heart disease in newborns. Adv Pediatr. 2015;62(1):211-26.

5. Peterson C, Ailes E, Riehle-Colarusso T, Oster ME, Olney RS, Cassell CH, et al. Late detection of critical congenital heart disease among US infants: estimation of the potential impact of proposed universal screening using pulse oximetry. JAMA Pediatr. 2014;168(4):361-70.

6. Mahle WT, Newburger JW, Matherne GP, Smith FC, Hoke TR, Koppel R, et al. Role of pulse oximetry in examining newborns for congenital heart disease: a scientific statement from the American heart association and american academy of pediatrics. Circulation. 2009;120(5):447-58.

7. Ewer AK. Review of pulse oximetry screening for critical congenital heart defects in newborn infants. Curr Opin Cardiol. 2013;28(2):92-6.

8. Lanker AM, Chowdhary J, Jeelani N, Jeelani S, Hassan AU, Wani N. Effectiveness of pulse oximetry screening for congenital heart disease in asymptomatic new-borns. Int J Res Med Sci. 2017;2(3):1112-6.

9. Chiappa E. The impact of prenatal diagnosis of congenital heart disease on pediatric cardiology and cardiac surgery. J Cardiovasc Med Hagerstown Md. 2007;8(1):12-6.

10. Garg LF, Van Naarden Braun K, Knapp MM, Anderson TM, Koppel RI, Hirsch $D$, et al. Results from the New Jersey statewide critical congenital heart defects screening program. Pediatrics. 2013;132(2):e314-23.

11. Abouk R, Grosse SD, Ailes EC, Oster ME. Association of US state implementation of newborn screening policies for critical congenital heart disease with early infant cardiac deaths. JAMA. 2017:318(21):2111-8. 
12. Grosse S, Peterson C, Abouk R, Glidewell J, Oster M. Cost and costeffectiveness assessments of newborn screening for critical congenital heart disease using pulse oximetry: a review. Int J Neonatal Screen. 2017;3(4):34.

13. Peterson C, Grosse SD, Oster ME, Olney RS, Cassell CH. Cost-effectiveness of routine screening for critical congenital heart disease in US newborns. Pediatrics. 2013;132(3):e595-603.

14. Roberts TE, Barton PM, Auguste PE, Middleton LJ, Furmston AT, Ewer AK. Pulse oximetry as a screening test for congenital heart defects in newborn infants: a cost-effectiveness analysis. Arch Dis Child. 2012;97(3):221-6.

15. Tobe RG, Martin GR, Li F, Mori R. Should postnatal oximetry screening be implemented nationwide in China? A cost-effectiveness analysis in three regions with different socioeconomic status. Int J Cardiol. 2016;204:45-7.

16. Minisiterio de Salud y Protección Social- Colciencias. Guía de práctica clínica. Detección de anomalías congénitas en el recién nacido. 2013. http://gpc.minsalud.gov.co/gpc_sites/Repositorio/Conv_500/GPC_rnac/ GPC_rnac_completa.aspx.

17. Ministerio de Salud y Protección Social. Resolución 5269 de 2017. 2017. http://www.consultorsalud.com/sites/consultorsalud/files/nuevo_plan_ de_beneficios_para_el_2018_-_resolucion_5269_de_2017.pdf.

18. Suárez-Ayala DV, Morcillo-Bastidas KL, Vallejo-Mondragón EL, ValenciaSalazar Al, Madrid-Pinilla AJ. Conocimiento y aplicación del tamizaje neonatal de cardiopatías congénitas críticas mediante el uso de oximetría de pulso. Rev Colomb Cardiol. 2016;23(6):553-9.

19. Samuel TY, Bromiker R, Mimouni FB, Picard E, Lahav S, Mandel D, et al. Newborn oxygen saturation at mild altitude versus sea level: implications for neonatal screening for critical congenital heart disease. Acta Paediatr. 2013;102(4):379-84.

20. Oximetry and neonatal examination for the detection of critical congenital heart disease: a systematic review and meta-analysis. F1000Research. https://f1000research.com/articles/8-242/v1. Accessed 8 Mar 2019.

21. DANE. Estadísticas vitales nacimientos y defunciones. https://www.dane. gov.co/index.php/estadisticas-por-tema/demografia-y-poblacion/nacim ientos-y-defunciones.
22. Grigore B, Peters J, Hyde C, Stein K. EXPLICIT: a feasibility study of remote expert elicitation in health technology assessment. BMC Med Inform Decis Mak. 2017;17(1):131.

23. Grigore B, Peters J, Hyde C, Stein K. A comparison of two methods for expert elicitation in health technology assessments. BMC Med Res Methodol. 2016. https://doi.org/10.1186/s12874-016-0186-3.

24. Tasa de cambio del peso colombiano (TRM). Banco de la República (banco central de Colombia). 2012. http://www.banrep.gov.co/es/trm. Accessed 12 Jul 2018.

25. gep_admin. Cuánto cuesta un funeral en Colombia sin seguro exequial. Grupo Empresarial Protección Ltda. 2016. https://www.grupoempresaria Iproteccion.com/2016/10/15/cuanto-cuesta-un-funeral-en-colombia/. Accessed 12 Jul 2018.

26. PIB per cápita (US\$ a precios actuales) | Data. https://datos.bancomundi al.org/indicador/NY.GDP.PCAP.CD. Accessed 12 Jul 2018.

27. Sullivan SD, Mauskopf JA, Augustovski F, Jaime Caro J, Lee KM, Minchin $M$, et al. Budget impact analysis - principles of good practice: report of the ISPOR 2012 budget impact analysis good practice II task force. Value Health. 2014;17(1):5-14

28. Instituto de Evaluación Tecnológica en Salud. Manual para la elaboración de análisis de impacto presupuestal. Bogotá D.C; 2014. http://www.iets. org.co/Manuales/Manuales/Manual\%20AIP\%20web_30\%20sep.pdf.

29. Raj M, Paul M, Sudhakar A, Varghese AA, Haridas AC, Kabali C, et al. Microeconomic impact of congenital heart surgery: results of a prospective study from a limited-resource setting. PLoS ONE. 2015;10(6):e0131348.

30. Mughal AR, Sadiq M, Hyder SN, Qureshi AU, Shah SS, Khan MA, et al. Socioeconomic status and impact of treatment on families of children with congenital heart disease. J Coll Physicians Surg. 2011;21(7):398-402.

\section{Publisher's Note}

Springer Nature remains neutral with regard to jurisdictional claims in published maps and institutional affiliations.
Ready to submit your research? Choose BMC and benefit from:

- fast, convenient online submission

- thorough peer review by experienced researchers in your field

- rapid publication on acceptance

- support for research data, including large and complex data types

- gold Open Access which fosters wider collaboration and increased citations

- maximum visibility for your research: over $100 \mathrm{M}$ website views per year

At BMC, research is always in progress.

Learn more biomedcentral.com/submissions 